29 Bronsky E, Bucholtz GA, Busse WW, Chervinsky P, Condemi J, Ghafouri MA, et al. Comparison of inhaled albuterol powder and aerosol in asthma. J Allergy Clin Immunol 1987;79:741-7.

30 Hartley JPR, Nogrady SG, Seaton A. Long-term comparison of salbutamol powder with salbutamol aerosol in asthmatic out-patients. $\mathrm{Br}$ J Dis Chest 1979:73:271-6.

31 Kou M, Kumana CR, Lauder IJ, Lam WK, Chan JCK. Bronchodilator responses to salbutamol using Diskhaler versus metered-dose inhaler. $J$ Asthma 1998;35:505-11

32 Seppala OP, Kari E, Elo E, Loyttyniemi E, Kunkel G. Comparison of the bronchodilating efficacies of a novel salbutamol metered dose powder inhaler and a pressurised metered dose aerosol with a spacer. Arzneimittelforschung 1998;48:919-23.

33 Custovic A, Taggart SC, Stuart A, Robinson A, Woodcock A. Efficacy of a new non-ozone depleting formulation for salbutamol. J Pharm Med $1995 \cdot 5 \cdot 161-8$

34 Laberge S, Spier S, Drblik SP, Turgeon JP. Comparison of inhaled ter butaline administered by either the Turbuhaler dry powder or a metereddose inhaler with spacer in preschool children with asthma. J Pediatrics 1994;124:815-7.

35 Parameswaran KN, Inman MD, Ekholm BP, Morris MM, Summers E, O'Byrne PM, et al. Protection against methacholine bronchoconstriction to assess relative potency of inhaled beta-2 agonists. Am J Respir Crit Care Med 1999;160:354-7.

36 Silvasti M, Laurikainen K, Nieminen M, Jarvinen M, Liippo K, Tammivaara R, et al. Single dose comparison between a novel multiple dose powder inhaler and a conventional metered dose inhaler in asthmatic patients. Acta Therapeutica 1993;19:125-35.

37 Giannini D, Di Franco A, Bacci E, Dente F, Taccola M, Vagaggini B, et al. The protective effect of salbutamol inhaled using different devices on methacholine bronchoconstriction. Chest 2000;117:1319-23.

38 Kemp JP, Furukawa CT, Bronsky EA, Grossman J, Lemanske RF Mansfield LE, et al. Albuterol treatment for children with asthma: a comparison of inhaled powder and aerosol. J Allergy Clin Immuno 1989;83:697-702.

39 3M Health Care. Four week safety and efficacy trial of Airomir inhaler and CFC-salbutamol inhaler in children with asthma. Loughborough: 3M Health Care (unpublished data in file 1141-SILV)

40 Golish J, Curtis-McCarthy P, McCarthy K, Kavuru M, Wagner W, Beck G, et al. Albuterol delivered by metered-dose inhaler (MDI), MDI with spacer and Rotahaler device-a comparison of efficacy and safety. I Asthm 1998:35:373-9.

41 Sellroos O, Pietinalho A, Riska H. Delivery devices for asthma medication. Clinical implications of differences in effectiveness. Clin Immunotherapy 1996;6:273-99.

42 Anderson PB, Stahl E, Hansen NCG. Terbutaline via Turbuhaler is effective in reversing metacholine-induced bronchoconstriction. J Clin Res 1998;1:49-54.

43 Boye K. A comparison of fenoterol powder capsules and fenoterol metered dose spray in bronchial asthma. Eur J Respir Dis 1983;64(suppl 130):9-11.

44 Hartley JP, Nogrady SG, Gibby OM, Seaton A. Bronchodilator effects of dry salbutamol powder administered by Rotahaler. Br J Clin Pharmacol 1977;4:673-5.

45 Kiviranta K. Fenoterol inhalation powder and aerosol in the treatment of asthma. Allergy 1985;40:305-7.

46 Hultquist C, Ahlstrom H, Kjellman NM, Malmqvist LA, Svenonius E, Melin S. A double-blind comparison between a new multi-dose powder inhaler (Turbuhaler) and metered dose inhaler in children with asthma. Allergy 1989;44:467-70.

47 Osterman K, Stahl E, Kallen A. Bricanyl Turbuhaler in the treatment of asthma: a six week multi-centre trial carried out in Sweden, the United Kingdom, Denmark, Norway and Finland. Eur Respir J 1991;4:175-9.

48 Bronsky E, Ekholm BP, Klinger NM, Colice GL. Switching patients with asthma from chlorofluorocarbon (CFC) albuterol to hydrofluoroalkane134a (HFA) albuterol. J Asthma 1999;36:107-14.

49 Ramsdell JW, Klinger NM, Ekholm BP, Colice GL. Safety of long-term treatment with HFA albuterol. Chest 1999;115:945-51.

50 Guyatt GH, Juniper EF, Walter SD, Griffith LE, Goldstein RS. Interpreting treatment effects in randomised trials. BMJ 1998;316:690-3.

(Accepted 11 July 2001)

\title{
Racial stereotyping: survey of psychiatrists in the United Kingdom
}

\author{
Helen Minnis, Alison McMillan, Marjorie Gillies, Shubulade Smith
}

Ten years ago, psychiatrists rated black male patients as potentially more violent than white patients. ${ }^{1}$ We aimed to establish whether such racial stereotyping still occurs.

\section{Participants, methods, and results}

We sent a postal questionnaire concerning the first presentation of a young man at casualty-which included a photograph, brief history, and findings on the patient's mental state-to a random sample (generated by SPSS statistical software) of 1000 British psychiatrists obtained from the Royal College of Psychiatrists' database. The sample was randomised so that half received a picture of a black man and half received a picture of a white man. (Photographs were of one of four healthy volunteers, whom we had not seen previously; they were matched for age and occupation, and photographed under identical conditions.) To exclude the possibility that results stemmed from differences between individual photographs, such as facial expression and mode of dress, we photographed two men from each race; one was a footballer and the other an academic (the photographs can be seen on BMJ's website). We used recommended terminology for ethnicity. ${ }^{2}$ Respondents were asked to rank five questions, in order of importance, to supplement the assessment. $\chi^{2}$ tests compared "black" with "white" questionnaires after questions were grouped into "important" (ranking 1-2) and "less important" (ranking 3-5). Respondents rated questions on management issues by putting a cross on a $10 \mathrm{~cm}$ continuous line. For each question, mean scores for "black" and "white" questionnaires were compared using the Mann-Whitney U test (table).

Of the 823 psychiatrists who could be contacted (18\% had changed address or retired), $59 \%(n=485)$ equivalent to $10 \%$ of British psychiatrists-returned completed questionnaires. Forty eight per cent (232) had received a "black" questionnaire. Fourteen respondents, who had all received a questionnaire with a photograph of a black man, guessed the hypothesis; six completed the questionnaire and were included in the analyses. Five others returned questionnaires uncompleted. Prior power calculations, based on expected mean (SD) risks of violence of 2.41 (1.76) $v$ $2.87(1.53),{ }^{1}$ gave the study $85 \%$ power at the $5 \%$ level.

Psychiatrists indicated that they were more likely to ask black patients whether they had a social worker or had received learning support at school, whereas they were more likely to ask white patients about problem drinking. They were equally likely to ask a black patient or a white patient if they had a criminal record or had recently used illegal drugs. Psychiatrists thought it would be more difficult to build a rapport with white patients, that white patients would be more of a management problem, and that they were more likely to pose a risk of violence to others. There were no significant differences regarding risk to self, the need for
Department of Child and Adolescen Psychiatry, Yorkhill NHS Trust, Glasgow G3 8SJ Helen Minnis specialist registrar in child psychiatry

Alison McMillan research assistant Marjorie Gillies nursing research fellow

Bethlem and Maudsley NHS Trust, London SE5 8AL

Shubulade Smith consultant psychiatrist Correspondence to: S Smith sphasms@iop.kcl. acuk

BMJ 2001;323:905-6

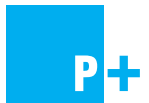

Photographs that accompanied the questionnaire can be seen on the $B M J$ 's website 
Differences between "black" and "white" questionnaires completed by British psychiatrists in ranking of questions on a $10 \mathrm{~cm}$ continuous line. Values are means (SD) unless otherwise stated

\begin{tabular}{|c|c|c|c|c|}
\hline Item on questionnaire & Black ( $\mathrm{n}=232)$ & White $(n=253)$ & Test statistic $(95 \% \mathrm{CI})^{*}$ & $P$ value \\
\hline \multicolumn{5}{|c|}{ Question likely to be asked of subject (\%)†: } \\
\hline Had a social worker & $\mathrm{n}=72 / 231(31)$ & $\mathrm{n}=47 / 227(21)$ & $\chi^{2}=6.52(0.02$ to 0.18$)$ & 0.01 \\
\hline Had learning support & $\mathrm{n}=24 / 231(10)$ & $\mathrm{n}=13 / 227(6)$ & $\chi^{2}=3.35(-0.003$ to 0.10$)$ & 0.06 \\
\hline Had a drinking problem & $n=106 / 231(46)$ & $\mathrm{n}=140 / 227(62)$ & $\chi^{2}=11.47(-0.25$ to -0.07$)$ & 0.001 \\
\hline Had a criminal record & $\mathrm{n}=38 / 231(16)$ & $\mathrm{n}=35 / 227(15)$ & $\chi^{2}=0.09(-0.06$ to 0.08$)$ & 0.80 \\
\hline Had recently used illegal drugs & $\mathrm{n}=224 / 232(96)$ & $\mathrm{n}=219 / 227(96)$ & $\chi^{2}=0.002(-0.03$ to 0.03$)$ & 0.90 \\
\hline Rapport difficult to establish & $62.4(18.3)$ & $68.4(16.2)$ & $23577.5(-9.00$ to -2.80$)$ & 0.01 \\
\hline Management problem & $61.7(16.1)$ & $66.9(16.6)$ & $22139.0(-8.10$ to -2.20$)$ & 0.001 \\
\hline Risk of violence to others & $52.6(20.4)$ & $57.8(19.9)$ & $63.5(-8.80$ to -1.55$)$ & 0.005 \\
\hline \multicolumn{5}{|l|}{ Likely diagnosis: } \\
\hline Schizophrenia & $77.8(17.3)$ & $83.0(13.5)$ & $3500.5(-8.00$ to -2.40$)$ & $<0.0001$ \\
\hline Personality disorder & $29.0(18.3)$ & $36.6(21.0)$ & $1408.5(-11.20$ to -4.00$)$ & $<0.0001$ \\
\hline Bipolar illness & $50.7(21.4)$ & $48.6(22.0)$ & $26037.0(-1.84$ to 6.00$)$ & 0.29 \\
\hline Brief reactive psychosis & $65.9(20.8)$ & $62.8(23.1)$ & $6308.5(-0.90$ to 7.00$)$ & 0.13 \\
\hline Neuroleptic drug indicated & $86.7(12.2)$ & $89.9(11.24)$ & $3575.0(-5.30$ to -1.10$)$ & 0.003 \\
\hline
\end{tabular}

*Mann-Whitney $\mathrm{U}$ unless otherwise stated. †Not all questions were ranked by all psychiatrists.

inpatient care, or the need for a locked ward. Psychiatrists were more likely to rate schizophrenia and personality disorder as appropriate diagnoses for white patients, but there were no differences for bipolar illness or brief reactive psychosis (table). There were no significant differences in any of the above variables between patients of the same race.

\section{Comment}

Participating psychiatrists did not rate black patients as more likely to be violent than white; this is different from a decade ago. ${ }^{1}$ Did psychiatrists guess the hypothesis and overcompensate? Only $1 \%$ suggested that they had overcompensated (none with a "white" questionnaire); in addition, ranking of supplementary questions in which psychiatrists with "black" photographs were more likely to ask about social work or learning support suggested that racial stereotyping was occurring. Differences in management strategies were small and may not be clinically important. Racism is evident in the psychiatric system: involuntary admissions of young black men are more common than those of young white men, ${ }^{34}$ and schizophrenia is more commonly diagnosed in young black men ${ }^{4}$ even though the prevalence in the community is no different for black and white men. ${ }^{5}$ Our results suggest that the racial stereotyping that occurs at first interview is not sufficient to account for the inequalities seen in secondary care. Urgent exploration is required to find out where these inequalities arise.

We are grateful to the Nuffield Foundation, the participants, the photographic volunteers, Lisa Cunningham and Reuben Millward for help with data collection, David Young for statistical advice, Stephen Keplinger for questionnaire design, and Peter Lynn and Glyn Lewis for advice on study design.

Contributors: HM initiated core ideas and participated in developing the protocol, supervising $\mathrm{AM}$, and writing the paper. AM discussed core ideas, completed the literature search, administered data collection, analysed the data, and participated in writing the paper. MG discussed core ideas and participated in developing the protocol, supervising AM, and writing the paper. SS discussed core ideas and participated in developing the protocol and writing the paper. HM is the guarantor.

Funding: Nuffield Foundation.

Competing interests: None declared.

1 Lewis G, Croft-Jeffreys C, David A. Are British psychiatrists racist? $\mathrm{Br} J$ Psychiatry 1990;157:410-5.

2 McKenzie K, Crowcroft NS. Describing race, ethnicity, and culture in medical research. BMJ 1996;312:1054-6.

3 Davies S, Thornicroft G, Leese M, Higgingbotham A, Phelan M. Ethnic differences in risk of compulsory psychiatric admission among representative cases of psychosis in London. BMJ 1996;312:533-7.

4 Koffman J, Fulop NJ, Pashley D, Coleman K. Ethnicity and use of acute psychiatric beds: one-day survey in North and South Thames regions. Br J Psychiatry 1997;171:238-41.

5 Nazroo JY. Ethnicity and mental health: findings from a community survey. London: Policy Studies Institute, 1997.

(Accepted 17 May 2001)

\section{One hundred years ago Nurses for the middle classes}

A correspondent writing to us on the occasion of the presentation of the Queen Victoria Jubilee Nurses, remarks that "the whole scheme of nursing appears to have been developed to the advantage of two classes, the very rich and the very poor,' and goes on to point out the difficulty of meeting the nursing cost of a severe or long illness with a moderate income. We quite agree with the writer; the middle classes are in this as in many other points at serious disadvantage, but we confess that we do not see from whence a remedy is to come. Of the many plans which have been tried, the only one that has survived is the nursing of the middle classes on the same lines as that of the district nurses, by means of the "visiting" or "daily" nurse, the fees being arranged on such a scale as, given a sufficiency of patients, the nurse is properly remunerated. In the case of many forms of illness this attendance is sufficient, but when the patient's condition is very grave, more continuous nursing is required and the expenditure is increased. Another scheme that has been tried is the hospital for the middle classes, but with the high rents and taxes and the cost of living it has been found impossible to work such a hospital on a small scale at fees within the reach of the patient, and there are other objections to this plan which need not now be particularised. The nurse's fee of two guineas a week, though it sounds high, is only sufficient to keep her during her short period of earning, and leaves very little for old age or sickness.

(BMJ 1901;ii:162) 